\title{
Hydrothermal-assisted Synthesis of $\mathrm{Li}_{2} \mathrm{FeSiO}_{4} / \mathrm{C}$ Composites as Cathode Materials for Lithium-Ion Batteries
}

\author{
Jing Li, Maolin Zhang ${ }^{*}$ Tongtong Xue, Dongyan Zhang, Yangxi Yan, Zhimin Li ${ }^{*}$ \\ School of Advanced Materials and Nanotechnology, Xidian University, Xi'an, 710071, China \\ *E-mail: mlzhang@xidian.edu.cn, zmli@mail.xidian.edu.cn
}

doi: $10.20964 / 2020.01 .80$

Received: 2 October 2019 / Accepted: 12 November 2019 / Published: 30 November 2019

\begin{abstract}
Orthosilicate $\mathrm{Li}_{2} \mathrm{FeSiO}_{4}$ composites have recently attracted increasing attention as cathode materials of lithium-ion batteries (LIBs). However, diffusion-controlled kinetics of electrochemical processes limited their widespread applications. Carbon coatings are often deposited to improve the electrochemical performances of $\mathrm{Li}_{2} \mathrm{FeSiO}_{4}$ based cathode materials. In this work, hydrothermal assisted sol-gel method was used to prepare $\mathrm{Li}_{2} \mathrm{FeSiO}_{4} / \mathrm{C}$ electrode materials using sucrose as carbon source. Structures, morphologies, and electrochemical behaviors of obtained cathode materials were analyzed by X-ray diffraction, scanning electron microscopy, electrochemical impedance spectroscopy and galvanostatic charge-discharge measurements. The electrode material prepared using $2 \mathrm{wt} \%$ sucrose displayed the best initial discharge specific capacity reaching $174 \mathrm{mAh} / \mathrm{g}$ at $0.1 \mathrm{C}$ and superior rate performance with $95.3 \%$ retention capacity. These improved electrochemical properties were attributed to well-developed hierarchical porous structure, enhanced Li-ion diffusion coefficient, and large exchange current of asobtained electrode materials.
\end{abstract}

Keywords: Cathode materials; $\mathrm{Li}_{2} \mathrm{FeSiO}_{4} / \mathrm{C}$; Electrochemical properties; Hierarchical porous structure

\section{FULL TEXT}

(C) 2020 The Authors. Published by ESG (www.electrochemsci.org). This article is an open access article distributed under the terms and conditions of the Creative Commons Attribution license (http://creativecommons.org/licenses/by/4.0/). 